\title{
The Interface and Fabrication Process of Diamond/Cu Composites with Nanocoated Diamond for Heat Sink Applications
}

\author{
Yaqiang Li ${ }^{1}$, Hongyu Zhou ${ }^{2}{ }^{\oplus}$, Chunjing $\mathrm{Wu}^{3}$, Zheng Yin ${ }^{4}$, Chang Liu ${ }^{1}$, Ying Huang ${ }^{1}$, Junyou Liu ${ }^{3, *}$ \\ and Zhongliang Shi ${ }^{5, *}$ \\ 1 Institute for Advanced Materials and Technology, University of Science and Technology Beijing, \\ Beijing 100083, China; yqli0677@163.com (Y.L.); cliu1381@163.com (C.L.); huangy@ustb.edu.cn (Y.H.) \\ 2 National Center for Materials Service Safety, University of Science and Technology Beijing, \\ Beijing 100083, China; hyzhou@ustb.edu.cn \\ 3 School of Materials Science and Engineering, University of Science and Technology Beijing, \\ Beijing 100083, China; cjwu@mater.ustb.edu.cn \\ 4 Qingdao Tianhe Manufacturing Transformation and Upgrading Research Institute Co., Ltd., \\ Qingdao 266400, China; 18653214699@163.com \\ 5 School of Materials Science and Engineering, Baise University, Baise 533000, China \\ * Correspondence: ljy568@yeah.net (J.L.); royshi88@163.com (Z.S.); \\ Tel.: +86-10-6233-2982 (J.L.); +86-135-6443-8276 (Z.S.)
}

Citation: Li, Y.; Zhou, H.; Wu, C.; Yin, Z.; Liu, C.; Huang, Y.; Liu, J.; Shi, Z. The Interface and Fabrication Process of Diamond/Cu Composites with Nanocoated Diamond for Heat Sink Applications. Metals 2021, 11, 196. https://doi.org/10.3390/ met11020196

Received: 10 December 2020

Accepted: 18 January 2021

Published: 22 January 2021

Publisher's Note: MDPI stays neutral with regard to jurisdictional claims in published maps and institutional affiliations.

Copyright: (c) 2021 by the authors. Licensee MDPI, Basel, Switzerland. This article is an open access article distributed under the terms and conditions of the Creative Commons Attribution (CC BY) license (https:// creativecommons.org/licenses/by/ $4.0 /)$.

\begin{abstract}
The coefficients of thermal expansion (CTE) and thermal conductivity (TC) are important for heat sink applications, as they can minimize stress between heat sink substrates and chips and prevent failure from thermal accumulation in electronics. We investigated the interface behavior and manufacturing of diamond/Cu composites and found that they have much lower TCs than copper due to their low densities. Most defects, such as cavities, form around diamond particles, substantially decreasing the high TC of diamond reinforcements. However, the measurement results for the $\mathrm{Cu}$-coated diamond/Cu composites are unsatisfactory because the nanosized copper layer on the diamond surface grew and spheroidized at elevated sintering temperatures. Realizing ideal interfacial bonding between a copper matrix and diamond particles is difficult. The TC of the $40 \mathrm{vol} \%$ Ti-coated diamond/Cu composite is $475.01 \mathrm{~W} \mathrm{~m}^{-1} \mathrm{~K}^{-1}$, much higher than that of diamond/Cu and $\mathrm{Cu}$-coated diamond/ $\mathrm{Cu}$ composites under equivalent manufacturing conditions. The minimally grown titanium layer retained its nanosized and was consistent with the sintering temperature. Depositing a nanosized titanium layer on a diamond surface will strengthen interfacial bonding through interface reactions among the copper matrix, nanosized titanium layer and diamond particles, reducing the interfacial thermal resistance and exploiting the high TC of diamond particles, even if defects from powder metallurgy remain. These results provide an important experimental and theoretical basis for manufacturing diamond/Cu composites for heat sink applications.
\end{abstract}

Keywords: heat sink; diamond/Cu composite; coefficient of thermal expansion; thermal conductivity; surface modification

\section{Introduction}

Microelectronics, especially power devices that follow Moore's Law, are undergoing miniaturization and integration with increasing speed and reliability requirements. Packaging materials and technologies with a high stability, high quality and specific performances are required for this [1]. In power devices, most failures are due to the thermal stress generated by temperature changes during service and the poor heat dissipation of the system. Thermal stress originates from a mismatch of the coefficients of thermal expansion (CTEs) between the heat sink material and the chip during the packaging and working state. It is necessary to solve the influence of alternating stresses caused by temperature changes 
on the reliability and normal working conditions of devices [2]. Herein, two key properties and characteristics of heat sink materials are summarized. On the one hand, they must have a high thermal conductivity (TC) to avoid an excessive temperature rise caused by heat accumulation which affects their ability to work normally. On the other hand, they must have a low CTE, similar to that of the chip, to avoid failure of the chips and devices caused by alternating stresses as the temperature changes. Therefore, with the development of chips, such as the first generation of Si semiconductors, the second generation of GaAs and InP semiconductors, and the third generation of $\mathrm{SiC}$ and $\mathrm{GaN}$ semiconductors, heat sink materials are still expected to have similar CTEs [3]. Metal matrix composites reinforced by ceramic particles, ceramic matrix composites and multicomponent alloys with composite structures are mainly used as heat sink materials at present [4]. In recent years, the research and development of diamond/Cu composites for heat sink applications is expected to make full use of the excellent thermal conductivity (TC) and low coefficient of thermal expansion (CTE) of diamond [5,6]. In addition, with the improvement of preparation technology and reduced cost of synthetic diamond, diamond/ $\mathrm{Cu}$ composites as heat management materials have recently received considerable attention in research and application $[7,8]$.

However, due to the weak interface and high thermal resistance as a result of chemical incompatibilities between diamond and $\mathrm{Cu}$, diamond/Cu composites reinforced by uncoated diamond particles cannot show high thermal conductivities, which are much lower than that of $\mathrm{Cu}$ itself. Some of the following references have reported similar results on the thermal conductivities of uncoated diamond/Cu composites prepared by different methods. Schubert et al. [9] studied a composite produced by hot pressing sintering that possessed a TC of $215 \mathrm{~W} \mathrm{~m}^{-1} \mathrm{~K}^{-1}$. Additionally, Chen et al. [10] illustrated that the obtained composites exhibited TC values as low as $200 \mathrm{~W} \mathrm{~m}^{-1} \mathrm{~K}^{-1}$ by a high-pressure high-temperature powder metallurgy (HPHT-PM) method. Sang et al. [11] produced a low TC (approximately $114 \mathrm{~W} \mathrm{~m}^{-1} \mathrm{~K}^{-1}$ ) for an uncoated diamond/copper composite fabricated by an infiltration method. Now, the method of coating the diamond particle surface with carbide-forming elements has been widely used to reduce the interface thermal resistance between diamond and $\mathrm{Cu}$ before the preparation of diamond/ $\mathrm{Cu}$ composites $[12,13]$. However, strengthening the interfacial bonding between diamond particles and the copper matrix is a function of their interface behaviors. Both Ciupinski et al. [14] and Wang et al. [15] revealed that the addition of the carbide-forming element chromium to a copper matrix effectively improved the TCs of composites. Li et al. [16] illustrated that a high TC was achieved in Ti-coated $\mathrm{Cu}$ /diamond composites fabricated by gas pressure infiltration.

This paper mainly focuses on the interface behavior and manufacturing process of copper matrix composites reinforced by diamond particles. In this work, two special surface modification methods for diamond particles were evaluated. One deposited a nanosized copper layer on the surfaces of the diamond particles by vacuum ion plating to improve the interfacial bonding between diamond particles and the copper matrix. The other involved the formation of a nanosized titanium layer on the surfaces of the diamond particles, which can form carbide with diamond and diffusion with copper at elevated sintering temperatures. Thus, the Ti coatings on the diamond surface can improve the wettabilities between diamond and liquid copper efficiently [17-20]. Additionally, it can also protect the diamond powder from the atmosphere and reduce the degree of graphitization at high temperatures [12]. Sun et al. [21] reported that a new reaction product, titanium carbide (TiC), at the interface played an important role in forming a high-strength joint between diamond and a brazing filler metal. Lin et al. [22] found that the mechanism behind the carbide's impact on the TC with $\mathrm{Cu}$-Ti-coated diamond particles was produced by a molten salt coating combined with magnetron sputtering. In theory, the two above-mentioned surface modifications for diamond particles can build "bridges" to link diamond particles with the copper matrix together through interfacial bonding. The regular powder metallurgy process was always selected as the fabrication process 
based on its suitability for large-scale production. We believe that the observed phenomena and obtained results can be utilized to provide an important experimental basis for the research of diamond/Cu composites.

\section{Materials and Methods}

\subsection{Raw Material Preparation}

Commercially available bulk copper (with a purity of $99.85 \mathrm{wt} . \%$ and size of $\sim 75 \mu \mathrm{m}$ from Zhongnuo New Material (Beijing) Technology Co., Ltd., Beijing, China) and synthetic single-crystal diamond particles (with sizes from 98 106 $\mu \mathrm{m}$ and type of MBD-4 from Henan Huanghe Whirlwind Co., Zhengzhou, China) were used to prepare the diamond/ $\mathrm{Cu}$ composites. Yamamoto et al. [23] revealed the dependence for the type $\mathrm{Ib}$ diamond on the nitrogen concentration by Fourier transform infrared spectroscopy (FTIR). In this paper, the synthetic (Ib-) diamond is of the MBD-4 type (HFD-B) and its thermal conductivity is about $1450 \mathrm{~W} \mathrm{~m}^{-1} \mathrm{~K}^{-1}$ due to its nitrogen content of $250 \mathrm{ppm}$ [12]. According to [24,25], the CTE values of diamonds and copper are $2.3 \times 10^{-6} \mathrm{~K}^{-1}$ and $16.5 \times 10^{-6} \mathrm{~K}^{-1}$, respectively. The TC value of pure copper is approximately $400 \mathrm{~W} \mathrm{~m}^{-1} \mathrm{~K}^{-1}$, according to [26]. The surfaces of the diamond particles were modified and deposited with a nanosized $\mathrm{Cu}$ or Ti layer by a vacuum ion plating process. The diamond/Cu composites were prepared with different volumes of diamond particles comprising 30, 40, 50 and 60 vol.\% under different powder metallurgy fabrication temperatures, as shown in Table 1.

Table 1. Thermal conductivities of the composites prepared under different conditions.

\begin{tabular}{|c|c|c|c|c|c|c|}
\hline Samples & $\begin{array}{c}V_{p}(\text { vol. } \%) / \\
\text { Temperature } \\
\text { (K) }\end{array}$ & $\begin{array}{c}\rho\left(\mathrm{g} \mathrm{cm}^{-3}\right) / \\
\text { Relative } \\
\text { Density }(\%)\end{array}$ & $C_{p}\left(\mathrm{~J} \mathrm{~g}^{-1} \mathrm{k}^{-1}\right)$ & $\begin{array}{c}a\left(\mathrm{~mm}^{2} \mathrm{~s}^{-1}\right) \\
\text { (Standard } \\
\text { Error) }\end{array}$ & $\begin{array}{c}\text { TC }\left(\mathrm{W} \mathrm{m}^{-1} \mathrm{~K}^{-1}\right) \\
\text { (Standard } \\
\text { Error })\end{array}$ & $\begin{array}{c}\text { CTE }\left(10^{-6} \mathbf{k}^{-1}\right) \\
\text { (Standard } \\
\text { Error) }\end{array}$ \\
\hline $\begin{array}{c}\text { Raw } \\
\text { diamond }\end{array}$ & $40 / 1243$ & $6.519 / 96.2$ & 0.410 & $\begin{array}{l}98.33 \\
(1.12)\end{array}$ & $\begin{array}{l}262.82 \\
(2.99)\end{array}$ & $\begin{array}{l}14.92 \\
(0.67)\end{array}$ \\
\hline \multirow{4}{*}{$\begin{array}{l}\text { Cu-coated } \\
\text { diamond }\end{array}$} & $40 / 1193$ & $6.525 / 96.3$ & 0.411 & $\begin{array}{l}89.51 \\
(0.95)\end{array}$ & $\begin{array}{l}240.05 \\
(2.55)\end{array}$ & $\begin{array}{l}13.57 \\
(0.40)\end{array}$ \\
\hline & $40 / 1243$ & $6.613 / 97.6$ & 0.412 & $\begin{array}{l}124.62 \\
(0.75)\end{array}$ & $\begin{array}{l}339.53 \\
(2.05)\end{array}$ & $\begin{array}{l}12.61 \\
(0.55)\end{array}$ \\
\hline & $40 / 1313$ & $6.579 / 97.2$ & 0.409 & $\begin{array}{l}115.98 \\
(0.46)\end{array}$ & $\begin{array}{l}312.08 \\
(1.24)\end{array}$ & $\begin{array}{l}12.94 \\
(0.48)\end{array}$ \\
\hline & $40 / 1363$ & $6.566 / 96.9$ & 0.410 & $\begin{array}{l}103.15 \\
(0.61)\end{array}$ & $\begin{array}{c}277.69 \\
(1.64)\end{array}$ & $\begin{array}{l}12.82 \\
(0.64)\end{array}$ \\
\hline \multirow{7}{*}{$\begin{array}{l}\text { Ti-coated } \\
\text { diamond }\end{array}$} & $30 / 1243$ & $7.219 / 98.6$ & 0.399 & $\begin{array}{l}157.20 \\
(0.69)\end{array}$ & $\begin{array}{l}452.80 \\
(1.98)\end{array}$ & $\begin{array}{l}13.22 \\
(0.44)\end{array}$ \\
\hline & $40 / 1193$ & $6.552 / 96.7$ & 0.409 & $\begin{array}{l}92.17 \\
(0.73)\end{array}$ & $\begin{array}{c}247.00 \\
(1.96)\end{array}$ & $\begin{array}{l}13.01 \\
(0.34)\end{array}$ \\
\hline & $40 / 1243$ & $6.661 / 98.3$ & 0.413 & $\begin{array}{l}171.01 \\
(0.95)\end{array}$ & $\begin{array}{l}470.45 \\
(2.63)\end{array}$ & $\begin{array}{l}11.24 \\
(0.35)\end{array}$ \\
\hline & $40 / 1313$ & $6.674 / 98.5$ & 0.412 & $\begin{array}{l}172.75 \\
(1.01)\end{array}$ & $\begin{array}{l}475.01 \\
(2.79)\end{array}$ & $\begin{array}{l}10.93 \\
(0.46)\end{array}$ \\
\hline & $40 / 1363$ & $6.620 / 97.7$ & 0.410 & $\begin{array}{l}151.94 \\
(0.91)\end{array}$ & $\begin{array}{l}412.40 \\
(2.46)\end{array}$ & $\begin{array}{l}11.86 \\
(0.36)\end{array}$ \\
\hline & $50 / 1243$ & $6.093 / 97.8$ & 0.422 & $\begin{array}{l}164.89 \\
(1.02)\end{array}$ & $\begin{array}{l}423.97 \\
(2.63)\end{array}$ & $\begin{array}{l}10.55 \\
(0.34)\end{array}$ \\
\hline & $60 / 1243$ & $5.485 / 96.5$ & 0.429 & $\begin{array}{l}160.15 \\
(0.81)\end{array}$ & $\begin{array}{c}376.84 \\
(1.89)\end{array}$ & $\begin{array}{l}9.93 \\
(0.40)\end{array}$ \\
\hline
\end{tabular}

\subsection{Composite Preparation}

The detailed preparation methods for the composites are described below. Diamond particles with different volume fractions were mechanically mixed with the pure copper powder for $2 \mathrm{~h}$, and then each cold-pressed sample was compacted under a pressure of $500 \mathrm{MPa}$ for $5 \mathrm{~min}$. Afterwards, the slurry was extruded at elevated temperatures in a 
graphite mold at a pressure of $50 \mathrm{MPa}$ and held for $10 \mathrm{~min}$ until it cooled down. The cooling rate was $10 \mathrm{~K} \mathrm{~min}^{-1}$ with circulating cooling water. These diamond/Cu composite samples had cylindrical shapes with diameters of $38 \mathrm{~mm}$ and thicknesses of $3 \mathrm{~mm}$, as shown in Figure 1b.
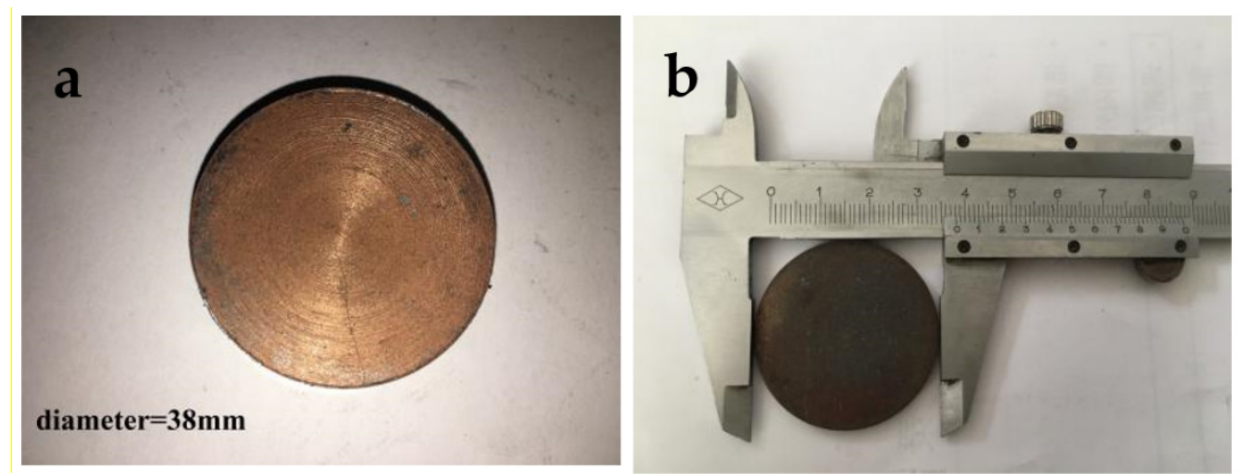

Figure 1. Pictures showing diamond/Cu composite samples: (a) cold pressed sample and (b) as-fabricated composite.

\subsection{Characterization}

A laser cutting machine and diamond wheel were used to prepare the composite samples. The surface microstructure and fracture morphology of the composites were characterized by field emission scanning electron microscopy (SEM, SUPRA 55, ZEISS, Germany). The thermal diffusivity $(\alpha)$ and specific heat capacity $\left(C_{p}\right)$ at constant pressure were both measured on a laser scattering TC instrument (LFA 427, NETZSCH, Germany) with cylindrical specimens that had diameters of $12.7 \mathrm{~mm}$ and thicknesses of $3 \mathrm{~mm}$. The TC was calculated as a product of the density $(\rho)$, specific heat capacity $\left(C_{p}\right)$ and thermal diffusivity $(\alpha)$. The CTE values were measured by a NETZSCH DIL 402C thermomechanical analyzer with cuboid-shaped specimens that had lengths of $25 \mathrm{~mm}$, widths of $4 \mathrm{~mm}$ and heights of $3 \mathrm{~mm}$. The densities of the composites were measured by the Archimedes method using distilled water as the immersion medium, and the measurement was repeated three times for each sample to reduce system error. The airtightness of the composites was tested by a helium mass spectrometer (ZQJ 530, KYKY TECHNOLOGY CO., LTD., Beijing, China). The samples were placed in helium at pressure of $5 \mathrm{MPa}$ for $3 \mathrm{~h}$, and the air leakage of each composite was measured.

\section{Results and Discussion}

\subsection{Surface Morphology of Cu-Coated and Ti-Coated Diamond Particles}

The surface morphologies of the (a) uncoated diamond particles, (b, c) Cu-coated diamond particles, and (d) Ti-coated diamond particles are shown in Figure 2. The thickness of the coating layer was approximately $100 \mathrm{~nm}$, and the particle size was approximately $35 \mathrm{~nm}$. Obviously, the raw diamond particles had flat and smooth surfaces, except for a small defect shown in Figure 2a. Either the copper layer or the titanium layer was coarser than the uncoated diamond surface, and all of the diamond particles retained their original shapes of a complete hexahedron octahedron after deposition. As presented in Figure $2 b, c$, the observed microstructure of the $\mathrm{Cu}$-coated diamond was convex and composed of continuous nanosized copper particles. As exhibited in Figure $2 \mathrm{~d}-\mathrm{f}$, the titanium layer was evenly distributed on the surface of the diamond particles. There were two different morphologies of the titanium layer on its surface, where nanosized particles with a $\{111\}$ preferred orientation and columnar structures with a $\{100\}$ preferred orientation were present. Moreover, the energy dispersive spectroscopy (EDS) mapping of titanium and carbon confirmed that all of the crystal planes were coated completely, as illustrated in Figure 3b,c. 

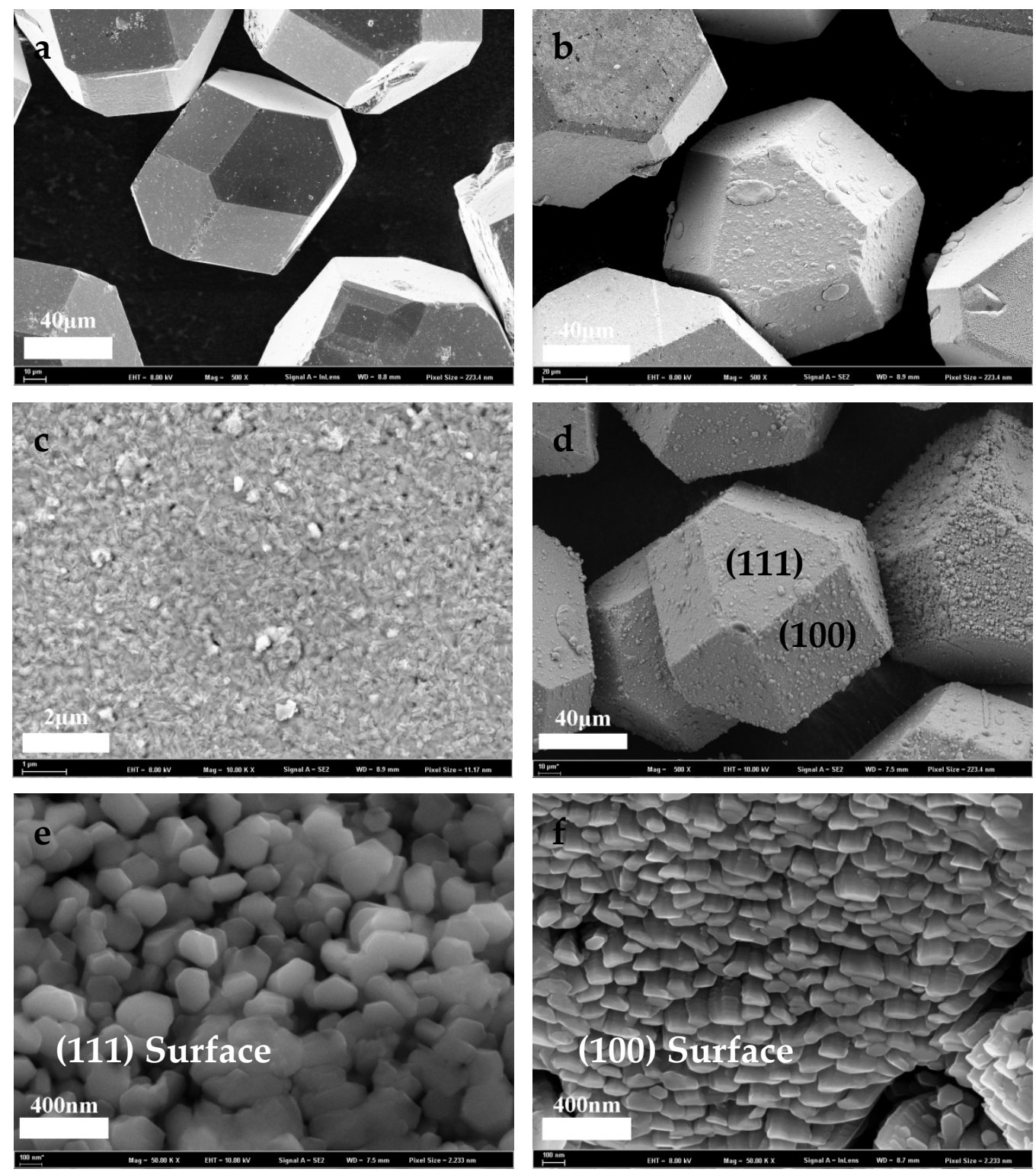

Figure 2. Scanning electron microscopy (SEM) images of the diamond particles: (a) uncoated diamond particles; (b,c) Cu-coated diamond particles; (d) Ti-coated diamond particles; (e,f) morphologies and orientations of Ti-coatings on diamond particles.
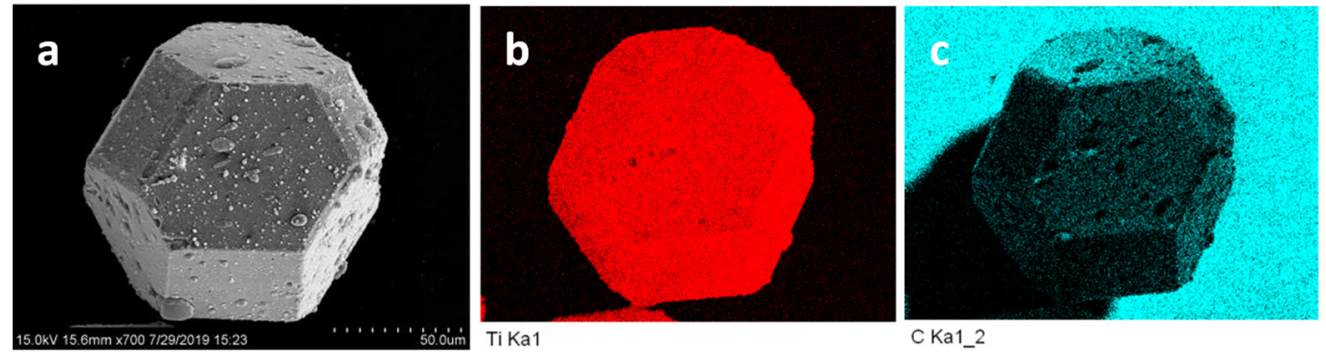

Figure 3. (a) SEM image of Ti-coated diamond particle for subsequent element mapping and (b,c) EDS mapping of Ti and $\mathrm{C}$, respectively. 


\subsection{Microstructures of the Composites}

It is necessary to achieve effective interfacial bonding between the diamond particles and copper matrix to reduce the thermal resistance. However, it is very difficult to produce effective interfacial bonding because of the poor interface wettability between diamond particles and copper powder or molten copper. Various defects, such as shrinkage cavities, gas films, gas nucleation and solute redistribution during the powder metallurgical process or solidification process, are generated and distributed around the interfaces in the composites, as observed by SEM. These factors hinder the connection of the diamond particles and copper matrix, which increases the interface thermal resistance and leads to a low TC value for the composites.

The fracture morphologies of the $40 \mathrm{vol} . \% \mathrm{Cu}$ /diamond composites fabricated with three kinds of diamond particles at a sintering temperature of $1243 \mathrm{~K}$ are shown in Figure 4. As illustrated in Figure $4 \mathrm{a}-\mathrm{d}$, both the uncoated and $\mathrm{Cu}$-coated diamond particles showed poor interfacial bonding with the copper matrix, and obvious cracks (shown by the white arrows) were generated between the diamond particles and copper. The corresponding relative densities and TC values were low, as calculated in Table 1. It should be noted that some cracks were present between the two phases due to the segregation of the copper coating (marked as a red circle in Figure $4 \mathrm{c}, \mathrm{d}$ ). The results show that these diamond particles were akin to cavities, were generated in the microstructure and substantially decreased the high TC of the diamond reinforcements. In contrast, Figure 4e,f shows that no cracks were observed in Ti-coated diamond/Cu composites, which indicates that the Ti-coating pretreatment process effectively strengthened the interfacial bonding between the diamond particles and copper matrix.
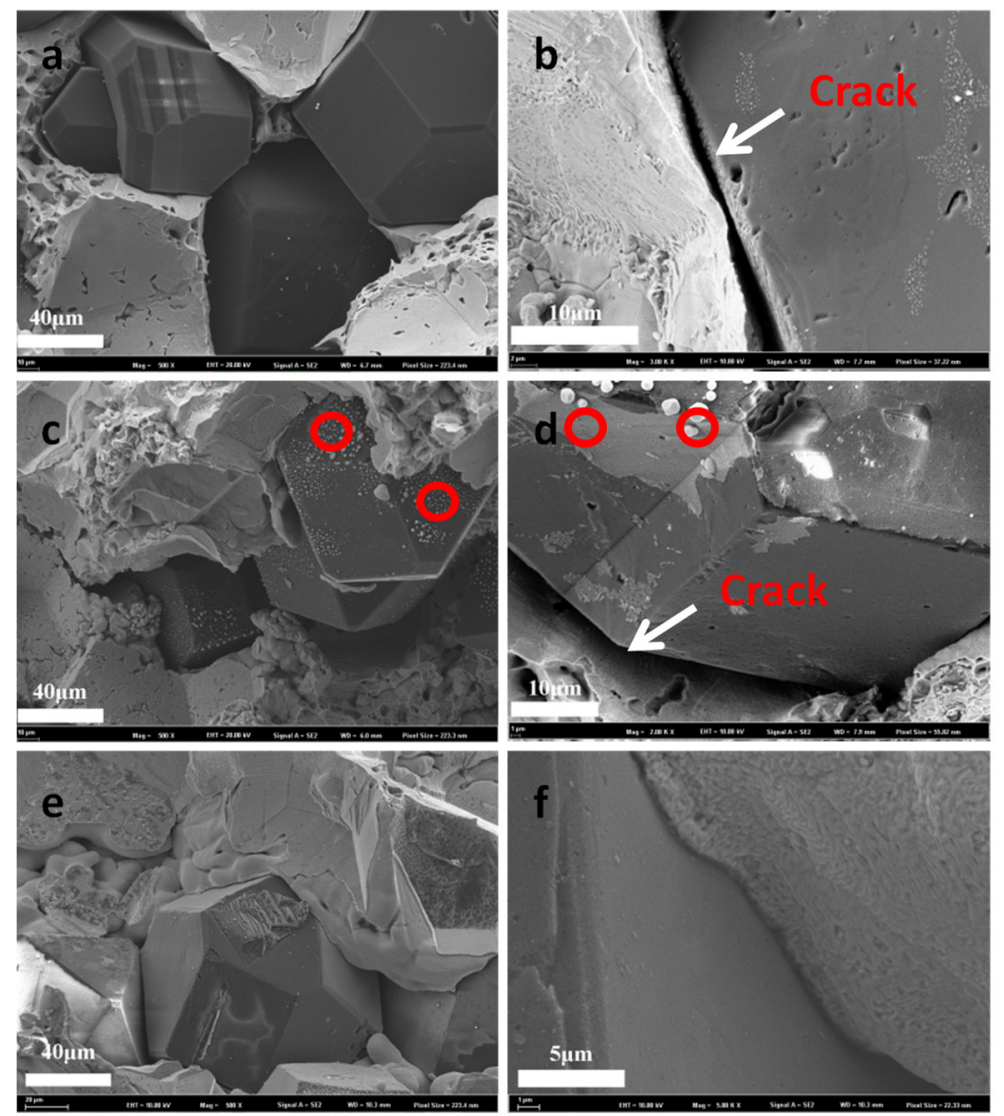

Figure 4. Fracture morphologies of the 40 vol. $\% \mathrm{Cu}$ /diamond composites fabricated at $1243 \mathrm{~K}$ based on $(\mathbf{a}, \mathbf{b})$ uncoated diamond particles; (c,d) Cu-coated diamond particles; (e,f) Ti-coated diamond particles. 


\subsection{Thermal Conductivities of the Diamond/Cu Composites}

The thermal diffusivity, specific heat and relative density of all prepared composite samples are summarized in Table 1 . The TC of the 40 vol.\% uncoated diamond $/ \mathrm{Cu}$ composite fabricated at $1243 \mathrm{~K}$ was $262.82 \mathrm{~W} \mathrm{~m}^{-1} \mathrm{~K}^{-1}$, which is much lower than that of $\mathrm{Cu}$. It also had a low relative density of approximately $96 \%$, and the remaining $4 \%$ was likely occupied by different defects, such as a gaseous film and shrinkage pores, due to the chemical incompatibility between the diamond and copper matrix. These defects covered the surface of the diamond particles and were equivalent to the cavities in the composites. The thermal conductivities and thermal diffusivities of diamond/Cu composites fabricated with three kinds of diamond powders at four sintering temperatures are illustrated in Figure 5a. The TC values of the diamond/Cu composites fabricated with $\mathrm{Cu}$-coated or Ti-coated diamonds first increased and then decreased with increasing sintering temperature. At the optimal temperatures of 1243 and $1313 \mathrm{~K}$, the maximum thermal conductivities achieved were 339.53 and $475.01 \mathrm{~W} \mathrm{~m}^{-1} \mathrm{~K}^{-1}$, respectively. When the sintering temperature was too low, defects, such as pores and cracks, were generated in the inhomogeneous and discontinuous copper matrix and exacerbated the decrease in the TC. Thus, the relative densities decreased, and the TC values were all significantly lower than that of pure copper at a sintering temperature of $1193 \mathrm{~K}$. Moreover, the matrix copper powder melted completely when the experimental temperature was $1363 \mathrm{~K}$, which is higher than the melting point of copper, and the interfacial thermal resistance increased when defects, such as shrinkage pores, were generated during the solidification of the copper. The resulting air gaps were caused by the different CTEs and the chemical incompatibility between the diamond and copper.
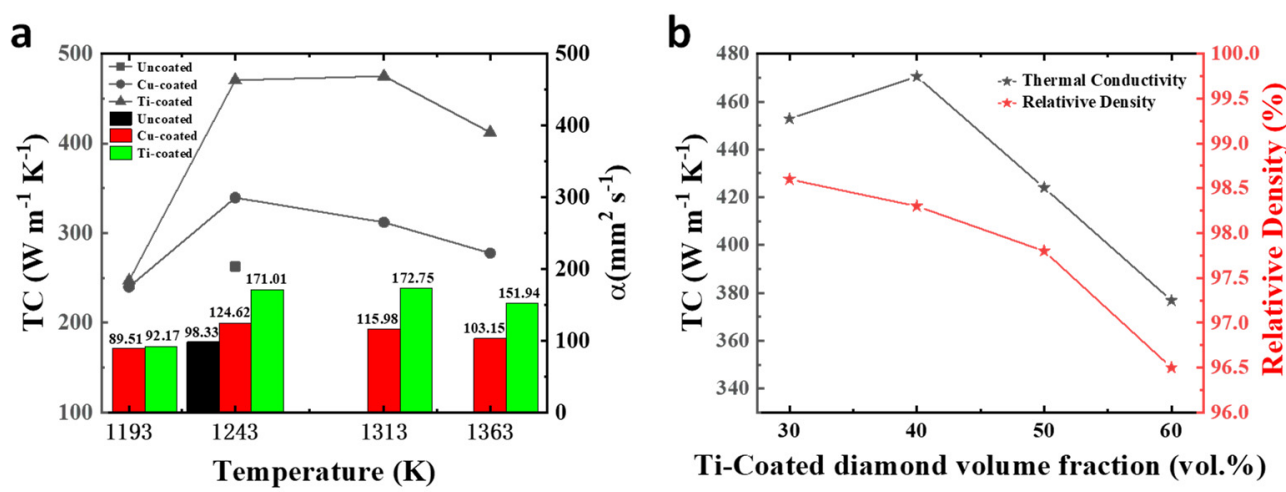

Ti-Coated diamond volume fraction (vol.\%)

Figure 5. (a) Thermal conductivity (TC) and thermal diffusivity of 40 vol. $\%$ uncoated diamond $/ \mathrm{Cu}, \mathrm{Cu}-\mathrm{coated}$ diamond/Cu, Ti-coated diamond/Cu composites under different temperatures; (b) TC and relative density for 30-60 vol.\% Ti-coated diamond/Cu composites fabricated at the same temperature of $1243 \mathrm{~K}$.

It is usually taken for granted that nanosized $\mathrm{Cu}$ deposited on the surface of diamond particles can greatly improve the interfacial bonding in $\mathrm{Cu}$-coated diamond/Cu composites. However, the interfacial bonding of the composites actually depends on the process temperature; this temperature is related to the segregation and spheroidization of the deposited nanosized $\mathrm{Cu}$ due to the "nano effect", which can be reflected by the thermal conductivities and relative densities of the composites. The TC value $\left(339.53 \mathrm{~W} \mathrm{~m}^{-1} \mathrm{~K}^{-1}\right)$ of the $40 \mathrm{vol} . \% \mathrm{Cu}$-coated diamond/Cu composite appeared to be higher than that of the $40 \mathrm{vol} . \%$ uncoated diamond/Cu composite, but it was much less than that of the 40 vol.\% Ti-coated diamond/Cu composite. When the $\mathrm{Cu}$ layer was replaced by a $\mathrm{Ti}$ layer, the TC of the corresponding composite reached $475.01 \mathrm{~W} / \mathrm{m} \mathrm{K}$ with a high relative density of $98.5 \%$. The relative densities of the $40 \mathrm{vol} . \%$ Ti-coated diamond/Cu composites reached $98.3 \%$ and $98.5 \%$ at 1243 and $1313 \mathrm{~K}$, respectively, and the corresponding TC values increased. These results indicate that the deposition of nanosized Ti on the surface of diamond particles effectively improved the interfacial bonding and TC. 
The thermal conductivities and relative densities of Ti-coated diamond/ $\mathrm{Cu}$ composites fabricated at the same temperature of $1243 \mathrm{~K}$ with four different diamond volume fractions are shown in Figure 5b. The change in the relative density shows that the surface pretreatment of the diamond particles by the nanosized Ti layer increased the relative density of the diamond/Cu composites to $98.3 \%$ or higher. With an increase in the volume fraction, the TC values tended to increase first and then decrease and reach a high TC (470.45 $\mathrm{W} \mathrm{m}^{-1} \mathrm{~K}^{-1}$ ) when the diamond particle content increased to 40 vol.\%. However, the relative densities decreased slightly with increasing the volume fraction of diamond particles due to the possibility of increasing interface defects. Therefore, the TC of the 50 vol.\% Ti-coated diamond/Cu composite was lower than that of the $40 \mathrm{vol} . \%$ Ti-coated diamond/Cu composite due to the continued decrease in the relative density, where the increasing trend of the interfacial thermal resistance exceeded that of diamond as the TC medium. However, the TC values for the 30-50 vol.\% Ti-coated diamond/Cu composites were still higher than that of $\mathrm{Cu}$, which means that diamond particles still had a partial effect. The interface defects mainly became the driving force when the volume fraction of Ti-coated diamond reached $60 \mathrm{vol} \%$, as its TC value was less than that of pure copper. Based on the above analysis, when the volume fraction of diamond is selected for use in a composite, the key to improving its TC value is to produce good interfacial bonding to minimize the interface defects between the diamond particles and the copper matrix through process control.

It is almost impossible to sinter diamond particles or diamond particles within a copper matrix together to establish continuous network structures. Based on our observations of the microstructure of the composite, only the network was linked by the copper matrix. The interfaces between the diamond particles and copper matrix as well as those between the diamond particles were discontinuous, and the diamond particles in the copper matrix network were equivalent to the cavities, similar to the defects distributed in the copper matrix. Eventually, the TC value of the composite was lower than that of the copper, which is contrary to the original intention of adding the diamond particles. Therefore, the interface design for the composites is very important for their manufacturing and engineering applications.

\subsection{Nano Effect Mechanism of the Copper Coating}

Based on the above analysis for the microstructure and TC values of the Cu-coated diamond/Cu composites, there was a nano effect in which the deposited nanosized copper particles behaved differently from the micron-sized particles. Ma et al. [27] reported the relationship between the sizes of metal nanoparticles and their melting points. Therefore, the melting points, which correspond to the size of the deposited nanosized copper particles, can be derived from Equations (1) and (2):

$$
\begin{aligned}
& T_{m}=T_{\infty} \exp \left(-\frac{2 \sigma M}{\rho_{m} \Delta_{f u s} H_{m} \frac{1}{r}}\right) \\
& T_{m}=1356 \exp \left(-\frac{1.743 \times 10^{-9}}{r}\right)
\end{aligned}
$$

Because it is difficult to measure the surface tension (specific surface free energy) of solids, and because anisotropy increases the complexity of the surface tension of crystals, the value of $\sigma_{\mathrm{Cu}}$ is approximately 1.6 , and its unit is $\mathrm{J} \mathrm{m}^{-2}$. The melting point of the nano layer was much lower than that of microscale particles, and the smaller the deposited nanosized copper particles were, the lower the melting point. Xue et al. [28] studied a way to qualitatively determine the melting points of metal nanoparticles, although it was not accurate for us to directly replace the density of the nanoparticles with the density of conventional bulk solids because the density of nanoparticles is smaller than that of conventional bulk solids. Some of the calculated melting points of copper nanoparticles with different particle sizes are illustrated in Table 2. 
Table 2. The melting point of copper nanoparticles as a function of the particle size.

\begin{tabular}{ccccccccccccc}
\hline $\boldsymbol{r} / \mathbf{n m}$ & $\mathbf{5}$ & $\mathbf{1 0}$ & $\mathbf{2 0}$ & $\mathbf{4 0}$ & $\mathbf{6 0}$ & $\mathbf{8 0}$ & $\mathbf{1 0 0}$ & $\mathbf{1 2 0}$ & $\mathbf{1 4 0}$ & $\mathbf{1 6 0}$ & $\mathbf{1 8 0}$ & $\mathbf{2 0 0}$ \\
\hline $\boldsymbol{T}_{\boldsymbol{m}} /{ }^{\circ} \mathbf{C}$ & 684 & 866 & 970 & 1025 & 1044 & 1054 & 1060 & 1063 & 1066 & 1068 & 1070 & 1071 \\
$\boldsymbol{T}_{\boldsymbol{m}} / \mathbf{K}$ & 957 & 1139 & 1243 & 1298 & 1317 & 1327 & 1333 & 1336 & 1339 & 1341 & 1343 & 1344 \\
\hline
\end{tabular}

Assuming that the copper nanoparticles deposited on the diamond surface were spherical, the spherical copper nanoparticles/layers segregated on the diamond surface due to the poor interface wettability with diamond at high temperature. Dorfman et al. [29] pointed out that the contact angle between carbon and copper is over $170^{\circ}$. Theoretically, the contact area between the deposited nanoparticles and diamond is inversely proportional to the radius of the particles, as calculated by Equation (3):

$$
\frac{S_{n}}{S_{0}}=\frac{r_{0}}{r_{n}}
$$

where it is assumed that the coating particles are spherical with radii of $r_{0}$ and total contact areas of $S_{0}$. Under different temperature conditions, the particle radius is $r_{n}$, and the total contact area is $S_{n}$.

Why does the $\mathrm{Cu}$-coated diamond/Cu composite not have the expected positive result? Generally, the selected sintering temperature was close to the melting point of pure copper $(1356 \mathrm{~K})$ because the melting point of the copper matrix was similar to that of bulk copper. Figure $6 \mathrm{~b}$ qualitatively shows the change in the particle size of the copper nanoparticles with an increase in the sintering temperature from 1193 to $1313 \mathrm{~K}$ (except for at $1363 \mathrm{~K}$ ), as estimated by Equation (2). With increasing temperature, the copper nanoparticles deposited on the diamond surface melted and grew locally on the diamond surface and became submicron- or micron-sized as a result of segregation and spheroidization, which were driven by the surface tension. However, the volume of the original deposited copper nano layer remained the same, but its size increased. As a result, the original uniformly distributed deposit was transformed into a local contact of micron or submicronsized copper particles, and the actual effect of the deposition of the nanosized copper layer on the diamond surface was greatly reduced during the sintering process, which significantly increased the interface thermal resistance of the composites. In addition, the copper matrix melted completely and was combined with the nanosized copper layer when the sintering temperature was $1363 \mathrm{~K}$ over the melting point, and the interface characteristics depended on the control of the copper solidification process. As discussed above, the nano effect of the copper nanoparticles deposited on the diamond particles exacerbated the increase in the interfacial thermal resistance, which directly affected the ideal interface design of the nanosized copper layer on the diamond surface.

a

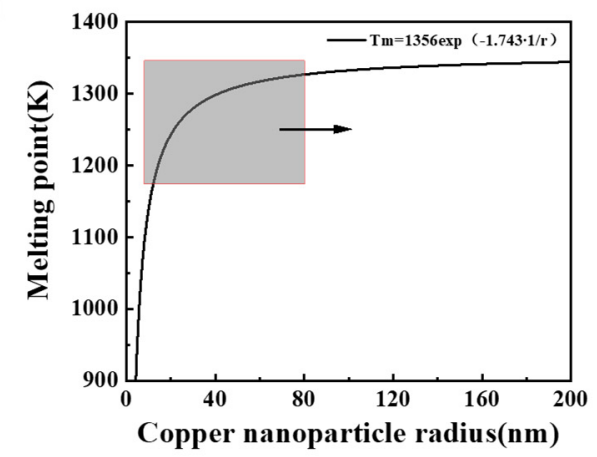

b

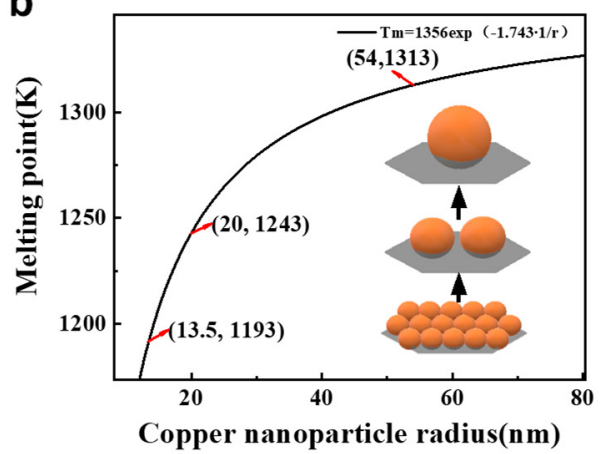

Figure 6. (a) The melting points of copper nanoparticles and (b) the segregation and growth of copper nanoparticles deposited on the diamond surface with increasing sintering temperature. 


\subsection{Nano Effect Mechanism of the Titanium Coating}

Similarly, by substituting the value of $\sigma_{T i}\left(1.588 \mathrm{~J} \mathrm{~m}^{-2}\right)$ into Equation (1), the melting points as a function of the size of the deposited nanosized titanium particles were calculated by Equation (4), and some of the calculated results are illustrated in Table 3:

$$
T_{m}=1660 \exp \left(-\frac{1.847 \times 10^{-9}}{r}\right)
$$

Table 3. The melting point of the titanium nanoparticles as a function of the particle size.

\begin{tabular}{ccccccccccccc}
\hline $\boldsymbol{r} / \mathbf{n m}$ & $\mathbf{5}$ & $\mathbf{1 0}$ & $\mathbf{2 0}$ & $\mathbf{3 0}$ & $\mathbf{4 0}$ & $\mathbf{5 0}$ & $\mathbf{6 0}$ & $\mathbf{7 0}$ & $\mathbf{8 0}$ & $\mathbf{9 0}$ & $\mathbf{1 0 0}$ & $\mathbf{1 1 0}$ \\
\hline $\boldsymbol{T}_{\boldsymbol{m}} /{ }^{\circ} \mathbf{C}$ & 874 & 1107 & 1241 & 1288 & 1312 & 1327 & 1337 & 1344 & 1349 & 1353 & 1357 & 1359 \\
$\boldsymbol{T}_{\boldsymbol{m}} / \mathbf{K}$ & 1147 & 1380 & 1514 & 1561 & 1585 & 1600 & 1610 & 1617 & 1622 & 1626 & 1630 & 1632 \\
\hline
\end{tabular}

Although the nanosized titanium layer was partially segregated at elevated temperatures, it was still uniform and covered the surface of the diamond particles, and there was good interfacial bonding between the diamond particles and the copper matrix during the sintering process. The EDS line-scan analysis across the interface between the copper and diamond is shown in Figure 7. The titanium element distribution at the interface sharply increased and was distributed well on the surface of the diamond. The nanosized titanium layer strengthened the interfacial bonding between the diamond particles and copper matrix. It can be seen that the interfaces for the nanosized Ti layer and diamond particles as well as the copper matrix were well combined. The good interfacial bonding of the composites was attributed to (1) the formation of $\mathrm{TiC}$ between the titanium and diamond and (2) the formation of $\mathrm{Cu}-\mathrm{Ti}$ intermetallic compounds or solid solutions, which effectively increased the interfacial wettability between the diamond and copper.
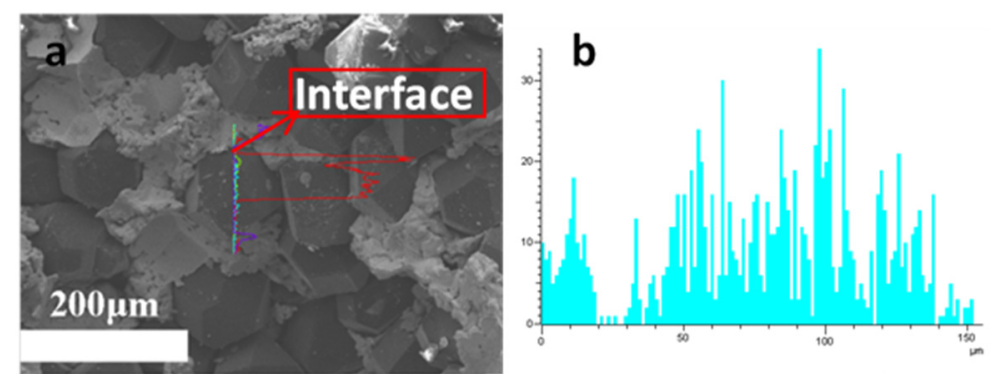

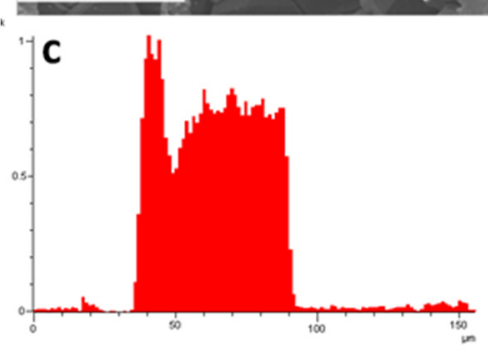

Carbon $\mathrm{Ka} 2$

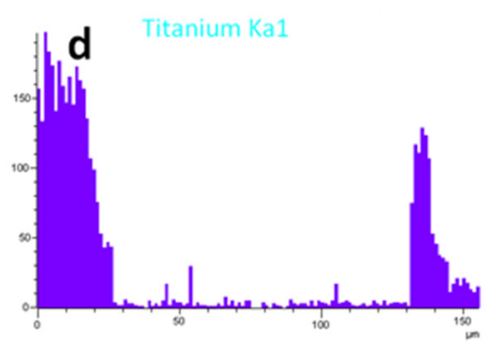

Copper Ka1

Figure 7. (a) Fracture morphology of the Ti-coated diamond/Cu composites and EDS line scans across the $\mathrm{Cu}$ /diamond interface for $(\mathbf{b}) \mathrm{Ti},(\mathbf{c}) \mathrm{C}$ and (d) $\mathrm{Cu}$.

Based on all data shown in Table 3, it can be seen that the nanosized titanium layer remained relatively constant when the selected sintering temperature was close to the melting point of copper. Furthermore, the deposited nanosized titanium layer built a bridge and linked the diamond particles with the copper matrix and played an important role in the interfacial bonding between the diamond and copper matrix. However, the thermal resistances from both the reaction layer and interfacial reaction phases had little effect 
on the composite materials because they were still in the nanometer scale range, and the interfacial microstructure was dense and did not contain defects.

Che et al. [30] reported that the chemical reaction between the nano titanium layer and diamond resulted in the formation of $\mathrm{TiC}$ nanoparticles under a vacuum environment at $990 \mathrm{~K}$. The titanium nanocoating on the diamond surface was usually approximately $30 \mathrm{~nm}$, so the TiC reaction product that formed between the diamond and coated layer was also nanosized, and its growth was limited. Based on our observations, the thickness of the deposited layer and even its microstructure for different diamond crystal planes were difficult to identify, as illustrated in Figure 2e,f. The formation mechanism of carbides was introduced in detail by Ruch et al. [31]. The anisotropy of the titanium deposition on the diamond surface might be explained by the gas desorption temperature and C-C bond force in the $\{100\}$ crystal planes being lower than those in the $\{111\}$ crystal planes. According to the experiment, the nanosized titanium coated on the diamond surface effectively improved the interfacial bonding between the diamond particles and copper matrix, which increased the TC of the composites.

\section{Conclusions}

The diamond/ $\mathrm{Cu}$ composites were fabricated by powder metallurgy with raw, $\mathrm{Cu}$-coated or Ti-coated diamond particles. The diamond/ $\mathrm{Cu}$ composites from direct combinations of diamond and $\mathrm{Cu}$ showed low thermal conductivities due to the chemical incompatibility between the diamond and copper matrix.

Generally, the deposition of copper nanoparticles on diamond particles may enhance the interfacial bonding between diamond and copper in the produced composites. However, it was difficult to ensure an ideal combination between the two phases because the deposition of a nanosized copper layer on diamond surfaces had a nano effect as a function of the sintering temperature. The copper readily segregated and spheroidized, which resulted in a low density and low TC values for the composites based on our theoretical calculation and experimental investigation.

The microstructures of the nanosized titanium layer deposited on the diamond surfaces were dependent on their orientations, as observed by SEM. According to our theoretical calculations and measurements, a nanosized titanium layer deposited on the surface of diamond particles, which was suitable for conventional powder metallurgical processes, could effectively improve the interfacial bonding between the diamond particles and $\mathrm{Cu}$ matrix. The highest TC obtained from the 40 vol.\% Ti-coated diamond/Cu composite reached $475.01 \mathrm{~W} \mathrm{~m}^{-1} \mathrm{~K}^{-1}$, owed to an improvement in the interfacial bonding and minimization of the interfacial thermal resistance.

Author Contributions: Y.L., Writing—original draft preparation and Methodology; H.Z., Writingreview and editing; C.W., Writing-review and editing; Z.Y., software; C.L., Formal analysis; Y.H., Formal analysis; J.L., Writing—review and editing; Z.S., Writing—review and editing. All authors have read and agreed to the published version of the manuscript.

Funding: This research was financially supported by the Beijing Science and Technology Plan from the Beijing Municipal Commission of Education (No. 2016041621601).

Data Availability Statement: The data presented in this study are openly available.

Acknowledgments: The authors gratefully acknowledge funding provided by the Fundamental Research Funds for the Central Universities (FRF-TP-19-012A1).

Conflicts of Interest: The authors declare no conflict of interest.

\section{References}

1. Li, J.W.; Wang, X.T.; Qiao, Y.; Zhang, Y.; He, Z.B.; Zhang, H.L. High thermal conductivity through interfacial layer optimization in diamond particles dispersed Zr-alloyed Cu matrix composites. Scr. Mater. 2015, 109, 72-75. [CrossRef]

2. Chu, K.; Wang, F.; Li, Y.B.; Wang, X.H.; Huang, D.J.; Geng, Z.R. Interface and mechanical/thermal properties of graphene/copper composite with Mo2C nanoparticles grown on graphene. Compos. Part A Appl. Sci. Manuf. 2018, 109, 267-279. [CrossRef] 
3. Zhou, H.Y.; Liu, X.; Yin, Z.; Li, Y.Q.; Liu, C.; Liu, S.B.; Wu, C.J.; Liu, J.Y. The fabrication of functional gradient hypereutectic Al-Si composites by liquid-solid separation technology. J. Alloys Compd. 2018, 763, 49-55. [CrossRef]

4. Jarzabek, D.M.; Chmielewski, M.; Wojciechowski, T. The measurement of the adhesion force between ceramic particles and metal matrix in ceramic reinforced-metal matrix composites. Compos. Part A Appl. Sci. Manuf. 2015, 76, 124-130. [CrossRef]

5. Yoshida, K.; Morigami, H. Thermal properties of diamond/copper composite material. Microelectron. Reliab. 2004, 44, 303-308. [CrossRef]

6. Ekimov, E.A.; Suetin, N.V.; Popovich, A.F.; Ralchenko, V.G. Thermal conductivity of diamond composites sintered under high pressures. Diam. Relat. Mater. 2008, 17, 838-843. [CrossRef]

7. Neubauer, E.; Angerer, P. Advanced composite materials with tailored thermal properties for heat sink applications. In Proceedings of the IEEE 2007 European Conference on Power Electronics and Applications, Aalborg, Denmark, 2-5 September 2007; pp. 2904-2911.

8. Chen, Y.J.; Young, T.F. Thermal stress and heat transfer characteristics of a Cu/diamond/Cu heat spreading device. Diam. Relat. Mater. 2009, 18, 283-286. [CrossRef]

9. Schubert, T.; Trindade, B.; Weissgarber, T.; Kieback, B. Interfacial design of Cu-based composites prepared by powder metallurgy for heat sink applications. Mater. Sci. Eng. A Struct. 2008, 475, 39-44. [CrossRef]

10. Chen, H.; Jia, C.C.; Li, S.J. Interfacial characterization and thermal conductivity of diamond/Cu composites prepared by two HPHT techniques. J. Mater. Sci. 2012, 47, 3367-3375. [CrossRef]

11. Sang, J.Q.; Yang, W.L.; Zhu, J.J.; Fu, L.C.; Li, D.Y.; Zhou, L.P. Regulating interface adhesion and enhancing thermal conductivity of diamond/copper composites by ion beam bombardment and following surface metallization pretreatment. J. Alloys Compd. 2018, 740, 1060-1066. [CrossRef]

12. Ren, S.B.; Shen, X.Y.; Guo, C.Y.; Liu, N.; Zang, J.B.; He, X.B.; Qu, X.H. Effect of coating on the microstructure and thermal conductivities of diamond-Cu composites prepared by powder metallurgy. Compos. Sci. Technol. 2011, 71, 1550-1555. [CrossRef]

13. Shen, X.Y.; He, X.B.; Ren, S.B.; Zhang, H.M.; Qu, X.H. Effect of molybdenum as interfacial element on the thermal conductivity of diamond/Cu composites. J. Alloys Compd. 2012, 529, 134-139. [CrossRef]

14. Ciupinski, L.; Kruszewski, M.J.; Grzonka, J.; Chmielewski, M.; Zielinsk, R.; Moszczynska, D.; Michalski, A. Design of interfacial Cr3C2 carbide layer via optimization of sintering parameters used to fabricate copper/diamond composites for thermal management applications. Mater. Des. 2017, 120, 170-185. [CrossRef]

15. Wang, L.H.; Li, J.W.; Catalano, M.; Bai, G.Z.; Li, N.; Dai, J.J.; Wang, X.T.; Zhang, H.L.; Wang, J.G.; Kim, M.J. Enhanced thermal conductivity in $\mathrm{Cu}$ /diamond composites by tailoring the thickness of interfacial TiC layer. Compos. Part A Appl. Sci. Manuf. 2018, 113, 76-82. [CrossRef]

16. Li, J.W.; Zhang, H.L.; Zhang, Y.; Che, Z.F.; Wang, X.T. Microstructure and thermal conductivity of Cu/diamond composites with Ti-coated diamond particles produced by gas pressure infiltration. J. Alloys Compd. 2015, 647, 941-946. [CrossRef]

17. Dong, Y.H.; Zhang, R.Q.; He, X.B.; Ye, Z.G.; Qu, X.H. Fabrication and infiltration kinetics analysis of Ti-coated diamond/copper composites with near-net-shape by pressureless infiltration. Mater. Sci. Eng. B Adv. Funct. Solid-State Mater. 2012, 177, 1524-1530. [CrossRef]

18. Cho, H.J.; Kim, Y.J.; Erb, U. Thermal conductivity of copper-diamond composite materials produced by electrodeposition and the effect of TiC coatings on diamond particles. Compos. Part B Eng. 2018, 155, 197-203. [CrossRef]

19. Molina-Jorda, J.M. Thermal conductivity of metal matrix composites with coated inclusions: A new modelling approach for interface engineering design in thermal management. J. Alloys Compd. 2018, 745, 849-855. [CrossRef]

20. Chang, G.; Sun, F.Y.; Duan, J.L.; Che, Z.F.; Wang, X.T.; Wang, J.G.; Kim, M.J.; Zhang, H.L. Effect of Ti interlayer on interfacial thermal conductance between $\mathrm{Cu}$ and diamond. Acta Mater. 2018, 160, 235-246. [CrossRef]

21. Sun, F.L.; Feng, J.C.; Li, D. Bonding of CVD diamond thick films using an Ag-Cu-Ti brazing alloy. J. Mater. Process. Technol. 2001, 115, 333-337. [CrossRef]

22. Lin, B.; Wang, X.; Zhang, Y.; Zhu, J.; Zhang, H. Interface characterization of a Cu-Ti-coated diamond system. Surf. Coat. Technol. 2015, 278, 163-170. [CrossRef]

23. Yamamoto, Y.; Imai, T.; Tanabe, K.; Tsuno, T.; Kumazawa, Y.; Fujimori, N. The measurement of thermal properties of diamond. Diam. Relat. Mat. 1997, 6, 1057-1061. [CrossRef]

24. Qing Yun, W.; Wei Ping, S.; Ming Liang, M. Mean and instantaneous thermal expansion of uncoated and Ti coated diamond/copper composite materials. Adv. Mater. Res. 2013, 702, 202-206. [CrossRef]

25. Hahn, T.A. Thermal expansion of copper from 20 to $800 \mathrm{~K}$-standard reference material 736. J. Appl. Phys. 1970, 41, 5096-5101. [CrossRef]

26. Raab, S.J.; Guschlbauer, R.; Lodes, M.A.; Korner, C. Thermal and electrical conductivity of $99.9 \%$ pure copper processed via selective electron beam melting. Adv. Eng. Mater. 2016, 18, 1661-1666. [CrossRef]

27. Ma, D.; Jie, W.; Liu, S.; Xu, W. Solute redistribution and growth velocity response in directional solidification process. J. Cryst. Growth 1996, 169, 170-174. [CrossRef]

28. Xue, Y.Q.; Zhao, Q.S.; Luan, C.H. The thermodynamic relations between the melting point and the size of crystals. J. Colloid Interface Sci. 2001, 243, 388-390. [CrossRef]

29. Dorfman, S.; Fuks, D.; Suery, M. Diffusivity of carbon in copper- and silver-based composites. J. Mater. Sci. 1999, 34, 77-81. [CrossRef] 
30. Che, Q.L.; Chen, X.K.; Ji, Y.Q.; Li, Y.W.; Wang, L.X.; Cao, S.Z.; Jiang, Y.G.; Wang, Z. The influence of minor titanium addition on thermal properties of diamond/copper composites via in situ reactive sintering. Mater. Sci. Semicond. Process. 2015, 30, 104-111. [CrossRef]

31. Ruch, P.W.; Beffort, O.; Kleiner, S.; Weber, L.; Uggowitzer, P.J. Selective interfacial bonding in Al(Si)-diamond composites and its effect on thermal conductivity. Compos. Sci. Technol. 2006, 66, 2677-2685. [CrossRef] 